\title{
IMPLEMENTATION OF HYBRID ENERGY SYSTEM IN INDIA
}

\author{
Priyavrat Bhardwaj ${ }^{1}$, Amar Deep Tanwar ${ }^{2}$ \\ ${ }^{I}$ Electrical \& Electronics Engineering, Guru Tegh Bahadur Institute of Technology, Delhi, India \\ ${ }^{2}$ Electrical \& Electronics Engineering, Guru Tegh Bahadur Institute of Technology, Delhi, India
}

\begin{abstract}
In India, a large number of areas are not connected to a power distribution system. Thus, Hybrid Renewable Energy resources can be used in those areas to sweep over this situation. It reduces the usage of conventional fuels thereby decreasing the emission of pollutants and is also cost-effective. In past five decades, the traditional power system which relies on oil and coal has given out a lot of harmful waste endangering our environmental conditions. These toxic wastes can only be stopped using greener and more reliable systems. Also the fuels used in generating power now-a-days in India is mostly non renewable resource which may not be available in the upcoming decades and are depleting day by day. Therefore hybrid systems are on the edge of being used more regularly. In order to implement Hybrid Renewable Energy in India, a village named Turakpur inside the city of Todabhim situated in Karauli district in the state of Rajasthan was selected to test out the conditions to implement it. A hybrid model on the proposed system is used to study those contiditions. Hence, green energy is used in an efficient manner instead of generating power through coal and oil as the former is available throughout the year.
\end{abstract}

Keywords- Renewable Energy, Photovoltaic, Wind Energy, Hybridization, Hybrid Grid, Hybrid Power System.

\section{INTRODUCTION}

The use of renewable energy or green energy for power distribution in remote areas is quiet prominent, as they are abundant in nature. Renewable energy is generally defined as energy from resources which exist over a wide geographical area and are replenished naturally. Wind, sunlight, tidal, geothermal heat, hydro, biomass are classified under renewable sources. Use of fossil fuels for power generation is a major factor of increased pollution level and climate change. Hybrid power system, on the other hand combine various renewable energy for power generation which are suitable for isolated communities residing in remote areas. A village named Todabhim in the state of Rajasthan, India was selected as a case to examine implementation of hybrid grid.

\section{HYBRID POWER SYSTEMS}

Hybrid Power Grid systems are generally used to federate Renewable energy sources with systems depending on oil and coal, that is a DG (Diesel Generator) Set being a primary source as well as an emergency backup. These systems can be enacted in devious areas instead of employing centralized grids. For instance, on a sunny day with insufficient wind speed (less than 3 meter/second) PV generators (solar panel systems) would compensate the electricity demand of the consumers. Also, in case on a windy \& cloudy day with insufficient solar energy wind power generators can fulfill the same.

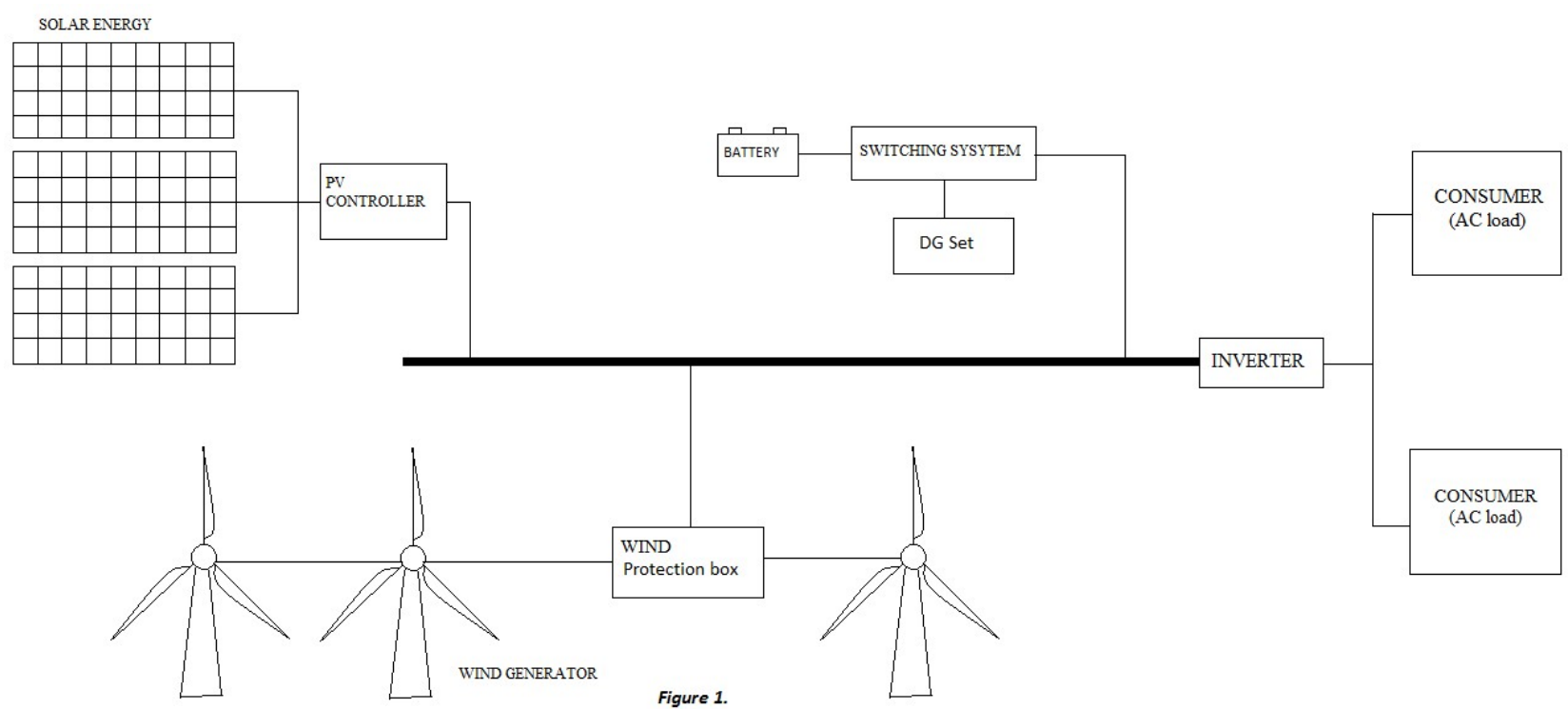

Fig 1: Proposed Hybrid Energy Model using Renewable energy as the secondary source 
A hybrid power system has been illustrated in Figure 1. (approximate schematic diagram of hybrid power grid). This grid can be used to consummate a $24 \times 7$ consumer power demand. Such systems, being stand-alone, can volunteer better performance. As there is an increasing electricity demand by the consumers and fossil fuels are decreasing day-by-day, therefore we can utilize hybrid systems and limit the use of fossil fuels thus making the power grid system more independent of oil and coal. According to an European survey the worldwide usage of solar energy capacity has already surpassed $100 \mathrm{GW}$ of installed power in 2012 which is 100 times more than the installed capacity 13 years earlier in 1999 [1]. In our case study, a village named Todabhim situated in Karauli district $\left(26.5^{\circ} \mathrm{N}, 77.02^{\circ} \mathrm{E}\right.$ and $260 \mathrm{~m}$ altitude, 5043 square $\mathrm{km}, 400-600 \mathrm{~m}$ from sea level) in the state of Rajasthan was selected since it has suitable solar and wind speed to implement the hybrid power system as described earlier. As per figure. 1 the major power is obtained by solar panel system, followed by wind turbines connected with a DG Set through a Busbar. The Diesel Generator is connected to a Battery as backup.

Table -1: Power consumption in various sectors

\begin{tabular}{|l|l|}
\hline $\begin{array}{l}\text { Per capita power consumption (kWh per } \\
\text { capita) }\end{array}$ & 0.00013 \\
\hline Domestic (MW) & 142.01 \\
\hline Industrial (MW) & 41.4 \\
\hline Commercial (MW) & 44.35 \\
\hline Average & 75.92 \\
\hline
\end{tabular}

On the practicability of using hybrid power system to supply the required load of the village all over the year. Thus Todabhim was selected for this purpose situated in Karauli district. It is located at $26.9167^{\circ} \mathrm{N}, 76.8167^{\circ} \mathrm{E}$ and it is about $113 \mathrm{~km}$ from Jaipur city (capital of Rajasthan).Note that the village is already connected to a power grid and an additional aim was set up to see the effect of using hybrid power system and to decide whether the village could depend on it. Karauli district has been ranked $12^{\text {th }}$ in power consumption in the state of Rajasthan [2]. The data of electricity power consumption in various sectors in Karauli district are given below in Table 1. (As per census 2001) [2].

\section{VILLAGE SELECTION}

Rajasthan has the highest solar insolence in the country and this makes it suitable for solar power projects. The aim of this case study was to pick a village in a state of Rajasthan to work.

\section{CASE STUDIES}

The optimal speed for generating electricity using wind turbine should be greater than $3 \mathrm{~m} / \mathrm{s}$. Figure 2 . demonstrates the wind speed variations across India [3]. Rajasthan has a wind speed variation range of 4 to $10 \mathrm{~km} / \mathrm{h}$ during the cold weather period and 20 to $30 \mathrm{~km} / \mathrm{h}$ in months of June and July during [4]. Therefore it is suitable for power generation using wind turbines. Figure 3 Demonstrates the solar variations across India [5]. India lies in a tropical region in the equatorial sun belt of earth. Thus it is rich in solar energy resource. The daily solar radiation varies over 5 to $7 \mathrm{kWh}$ per square meter. Abundant sunshine throughout the year in Rajasthan can be used for generation of electricity. The average sunny hours vary from 9.8 hours in summers to 9.3 hours in winters [4]. Thus both of these renewable energies can be used together to provide a sufficient electricity supply to various sectors. In case if the conventional grid is down, then the proposed hybrid model can be enacted. As these are green and more reliable resources of energy.

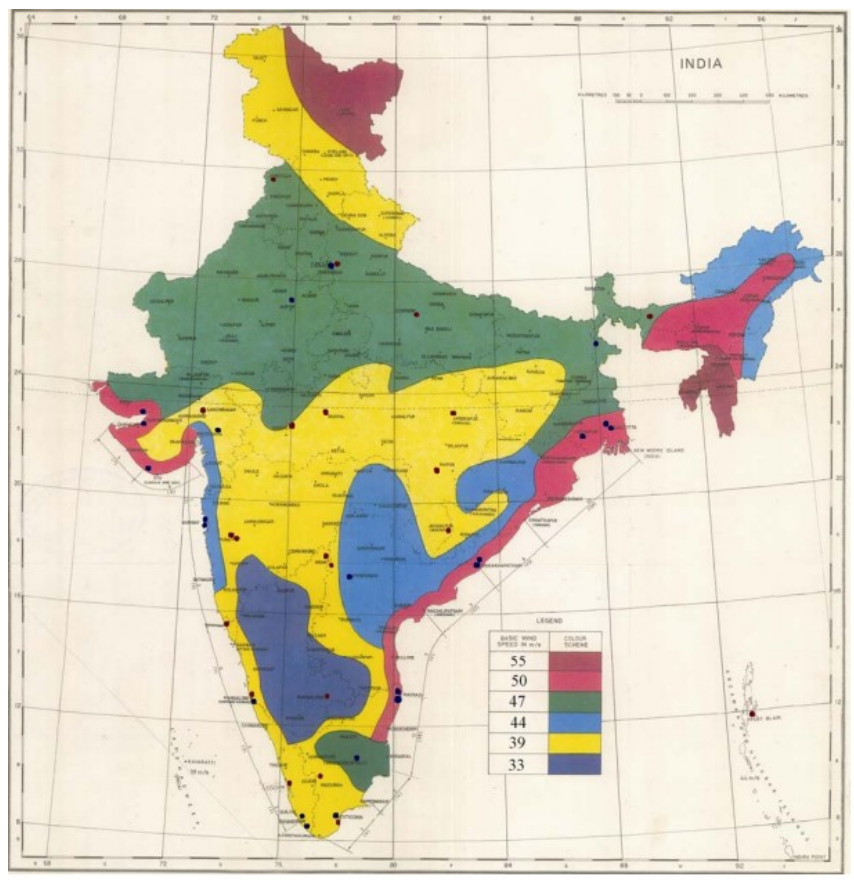

Fig 2: Wind Speed map at 45 IMD stations.

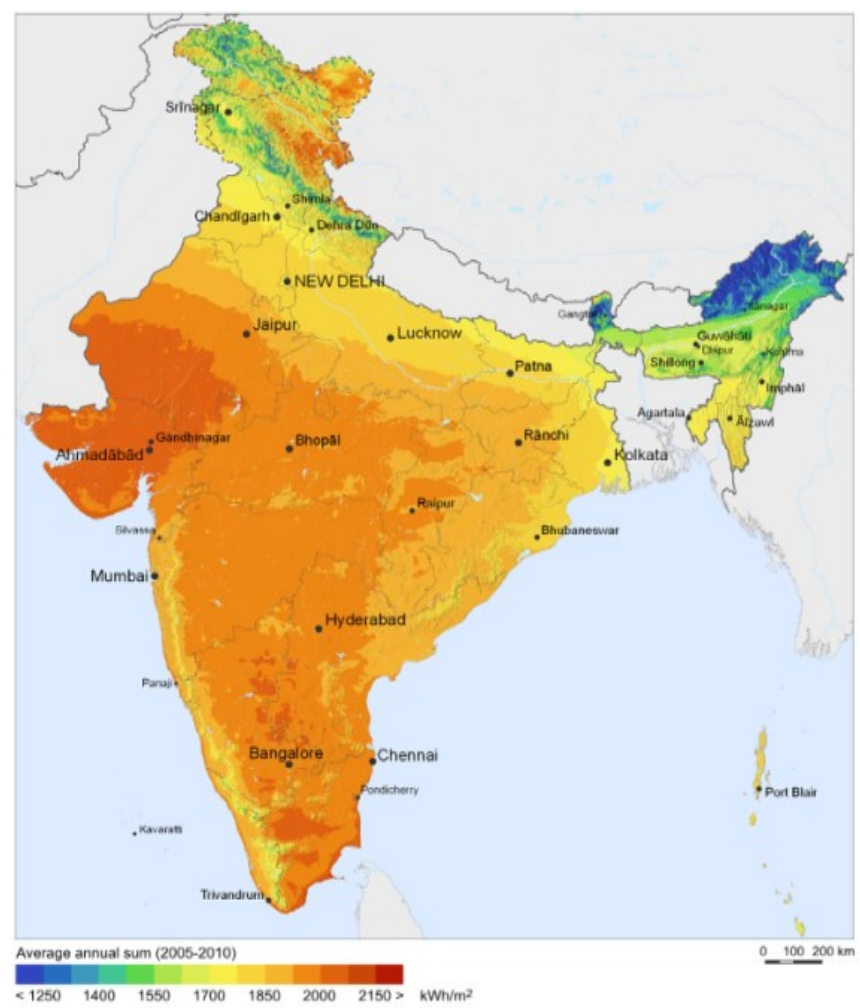

Fig 3: Solar Irradiation map of India 


\section{RESULT}

In India, the total wind and solar power capacity installed in year 2012 is $9146.95 \mathrm{MW} /$ hour [6]. As per table 2, there has been an exponential increase in fuel price over last 26 years in India and are also on a verge of depletion [7]. As per a study, between 2050 and 2075, the projected crude oil reserves will get depleted [8]. Hence due to scarcity of conventional fuels (oil and coal), hybrid models would become a more reliable method for providing electricity. Hybrid models are very cost effective as compared to oil and coal on a long runtime.

Table 2: Rise in fuel price in India (INR)

\begin{tabular}{|l|l|l|l|}
\hline Year & Petrol & Diesel & LPG \\
\hline Apr-89 & 8.5 & 3.5 & 57.6 \\
\hline Oct-90 & 12.23 & 5.05 & 57.6 \\
\hline Jul-91 & 14.62 & 5.05 & 67.9 \\
\hline Jul-96 & 21.13 & 9.04 & 119.95 \\
\hline Jun-98 & 23.94 & 9.87 & 136 \\
\hline Jan-00 & 25.94 & 14.04 & 146 \\
\hline Nov-00 & 28.7 & 16.55 & 232.25 \\
\hline Oct-02 & 30.24 & 19.23 & 241.2 \\
\hline Mar-03 & 33.49 & 22.12 & 241.2 \\
\hline Nov-04 & 39 & 26.28 & 281.6 \\
\hline Jun-05 & 40.49 & 28.45 & 281.6 \\
\hline Jun-06 & 47.51 & 32.47 & 281.6 \\
\hline Jul-08 & 50.62 & 34.86 & 304.7 \\
\hline Jul-09 & 44.63 & 32.87 & 279.7 \\
\hline Jul-10 & 51.45 & 40.1 & 345.35 \\
\hline Jan-11 & 58.37 & 37.75 & 345.35 \\
\hline Jul-11 & 63.66 & 41.27 & 395.35 \\
\hline
\end{tabular}

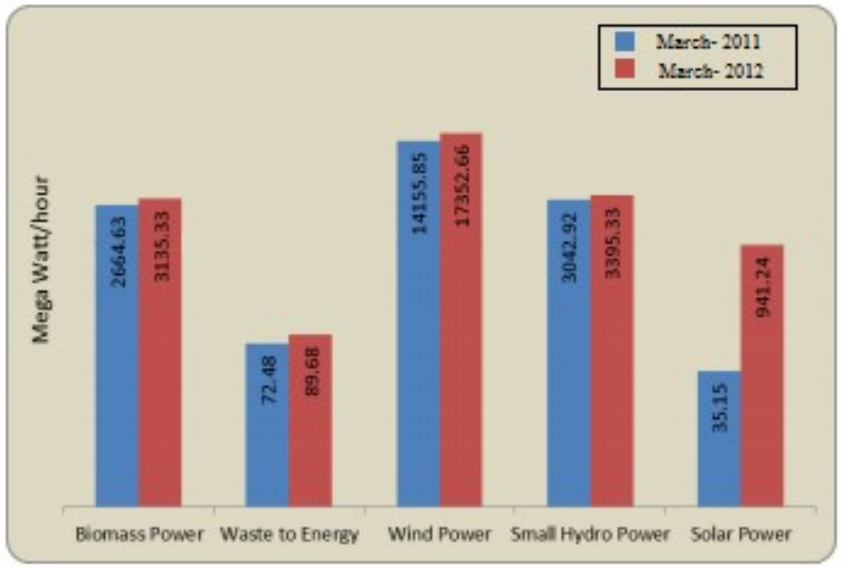

Fig 4: Installed Renewable power in India

These systems require single time cost investment for installation while the traditional fuel dependent system requires a regular investment along with maintenance and shipment cost. Also the economic Payback time, which is usually from 1 to 7 years for most PV systems, is efficient. Not only the economic payback time is favorable but also, on considering the policy based factors such as subsidies and Feed-in tariffs, can affect national investments and savings. Considering the Levelized Cost of Electricity (LCOE), which is the cost per kilowatt hour of electricity produced by a power generation project, the power producer must sell the electricity at a price higher than the LCOE so as to make profit. We can also consider Grid Parity, which is a situation at which the PV power can be generated at a levelized cost that is equal to the power price from the conventional electric grid, which on comparing with whole sale price Grid Parity of the proposed hybrid system can be reached faster. Grid Parity for renewable energy based power systems such as hybrid systems are now reaching at a global level. Hence a hybrid model can behave as a reliable source of energy seemingly starting a whole new tradition, where the power generation is mainly from renewable resources. This will apparently reduce the concentration of toxicants in atmosphere as well as on our planet earth.

\section{CONCLUSION}

Hybrid systems being the most promising application in today's world are of great importance. Hybrid grids are an emerging technology which can eliminate the hazardous effect of emitted gases from combustion of fuels which have been used for generating power since its invention. Now a days, hybrid systems are being implemented in various fields such as automation, domestic usage etc. This approach of using hybrid models would not only help in village electrification but it will also be more significant as it's implementation is a smarter approach towards conservation of our environment ultimately making power grid smarter.

\section{REFERENCES}

[1] "Solar Energy", MOOC (edx), TU Delft, Netherlands, September 2015 , https://courses.edx.org/courses/coursev1:DelftX+ET3034x+3T2015/courseware/8cbd1aac88 $77451 \mathrm{f} 8 \mathrm{a} 0011 \mathrm{ac} 2095 \mathrm{f} 8 \mathrm{c} 6 / 0 \mathrm{ce} 9 \mathrm{~d} 4 \mathrm{a} 1 \mathrm{f6ca} 47 \mathrm{ddbf3} 8 \mathrm{e} 518$ 3bbe685e/

[2] Dr. Sudhir Varma, Director, Social Policy Research Institute, "A Study on Inter Regional Economic Inequalities in Rajasthan", Jaipur, http://planningcommission.nic.in/reports/sereport/ser/st dy_rgeco.pdf

[3] N. Lakshmanan, S. Gomathinayagam*, P. Harikrishna, A. Abraham and S. Chitra Ganapathi, "Basic wind speed map of India with long-term hourly wind data", Structural Engineering Research Center, Chennai, India.

indiaenvironmentportal.org.in/files/wind $\% 20$ speed $\% 20$ data.pdf

[4] P. Koteswaram Fna, Director-General of Observatories Meteorological Office, "Meteorology and Climatology of the Rajasthan Desert", New Delhi. http://www.dli.gov.in/data_copy/upload/INSA/INSA_2 /20005a14_401.pdf

[5] Krupali, "Solar Irradiation Data of India". http://www.eai.in/club/users/krupali/blogs/627

[6] Energy Statistics 2013, Twentieth Issue, Ministry of Statistics and Programme Implementation, New Delhi. 
http://mospi.nic.in/mospi_new/upload/Energy_Statistic s_2013.pdf

[7] Nidhi Verma, "Fuel Prices in India's Capital Since 1989". http://in.reuters.com/article/2011/06/24/indiafuel-idINL3E7HN2FT20110624

[8] World Fossil Fuel Reserves and Projected Depletion, The Colorado River Commission of Nevada, March 2002.

http://crc.nv.gov/docs/world\%20fossil\%20reserves.pdf

[9] Essam A. Al-Ammar, Nazar H.Malik, Mohammad Usman, "Application of Using Hybrid Renewable Energy in Saudi Arabia" King Saud University, ETASR vol.1, No. 4, 2011, 84-89. 